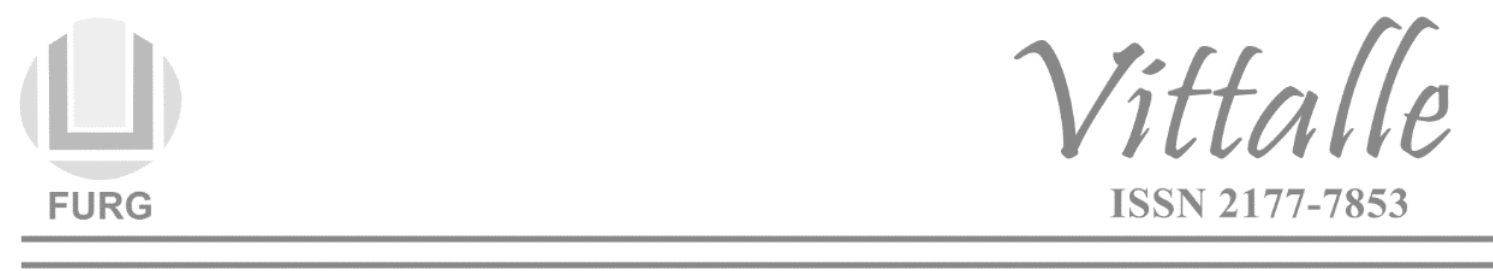

\title{
Ventilação mecânica
}

\author{
Karine Cristina Ghiggi ${ }^{*}$, Guilherme Brandão Almeida ${ }^{\mathrm{a}}$, Lázaro Fagundes Audino ${ }^{\mathrm{b}}$ \\ ${ }^{\text {a}}$ Faculdade de Medicina, Universidade Federal do Rio Grande, Rio Grande, RS, Brasil \\ ${ }^{\mathrm{b}}$ Hospital Regional do Oeste, Chapecó, SC, Brasil
}

\begin{abstract}
RESUMO
A ventilação mecânica é uma modalidade de suporte de vida avançado essencial para

Palavras-chave:

Insuficiência respiratória;

Respiração Artificial;

Competência Clínica;

Ensino; Medicina.

pacientes que evoluem para quadros graves. Quando empregado como ferramenta de diagnóstico, o ventilador fornece dados sobre a conformidade estática do sistema respiratório e a resistência das vias aéreas. O cenário clínico e os dados obtidos do ventilador permitem ao clínico fornecer ventilação mecânica invasiva eficaz e segura através da manipulação das configurações do ventilador. O conhecimento dos conceitos básicos e da utilização prática da ventilação mecânica é indispensável para médicos que pretendem trabalhar nas áreas de emergência e medicina intensiva. Este capítulo tem por objetivo apresentar os conceitos básicos da ventilação mecânica e correlacionar com a mecânica ventilatória do paciente.

\section{Mechanical ventilation}

Keywords:

Respiratory Insufficiency;

Respiration, Artificial;

Clinical Competence;

Teaching; Medicine.

\section{ABSTRACT}

Mechanical ventilation is an essential life support modality essential for patients who progress to severe conditions. When employed as a diagnostic tool, the ventilator provides data on the static compliance of the respiratory system and airway resistance. The clinical scenario and the data obtained from the ventilator allow the clinician to provide effective and safe invasive mechanical ventilation through manipulation of the ventilator settings. The knowledge of the basic concepts and practical use of mechanical ventilation is essential for physicians who intend to work in the areas of emergency and intensive care medicine. This article aims to present the basic concepts of mechanical ventilation and to correlate with the ventilatory mechanics of the patient.
\end{abstract}

\section{Introdução}

Ventilação mecânica (VM) é uma modalidade de suporte de vida avançado cujo objetivo é melhorar as trocas gasosas, reduzir o trabalho respiratório, aumentar os níveis de oxigenação, diminuir a hipercapnia e a acidose respiratória e permitir melhora da relação ventilação/perfusão (V/Q) pulmonar em pacientes com insuficiência respiratória aguda (IRA) (1,2). A VM pode ser não invasiva (VNI), com uso de máscaras faciais, ou invasiva (VMI), através de tubo endotraqueal ou cânula de traqueostomia (2).

Em emergências e unidades de terapia intensiva (UTIs) é comum o uso de ventiladores mecânicos como ferramenta indispensável em muitos casos (1). Durante a ventilação espontânea, o paciente deve desenvolver, através dos músculos respiratórios, uma força inspiratória capaz de vencer as forças de atrito e viscoelásticas presentes no sistema ventilatório; essa força deve ser a necessária para movimentar determinado volume de gás através das vias aéreas até os alvéolos, promovendo, dessa forma, as trocas gasosas $(1,3)$. Assim, quando há uma doença pulmonar, ocorre maior resistência, levando a um maior esforço muscular por parte do paciente e o predispondo mais facilmente a fadiga dos músculos respiratórios $(1,3)$. Nesse caso, a VM promove, através da pressão positiva

\footnotetext{
*Autor correspondente: karine.ghiggi@ gmail.com (Ghiggi K. C.)
} 
instituída no sistema pulmonar, a capacidade de bombear os gases para dentro dos pulmões de forma cíclica e aliviar esse esforço por parte do paciente (1).

Diante desse contexto, o conhecimento de alguns aspectos e ajustes iniciais são essenciais aos médicos que trabalham nestas áreas. Assim, este capítulo tem por objetivo apresentar os conceitos básicos da ventilação mecânica e correlacionar com a mecânica ventilatória do paciente.

\section{Fisiologia respiratória aplicada à ventilação mecânica}

$\mathrm{O}$ ar, assim como outros fluidos, move-se de regiões de alta pressão para regiões de baixa pressão $(4,5)$. Sob circunstâncias normais, a inspiração é realizada quando a pressão alveolar diminui abaixo da atmosférica (1). Quando se discute a mecânica da respiração, a pressão atmosférica é convencionalmente referida como zero centímetros de água (0 $\mathrm{cmH}_{2} \mathrm{O}$ ); por isso, a redução da pressão alveolar abaixo da atmosférica é conhecida como respiração com pressão negativa (4). A ventilação apresenta duas fases: inspiração e expiração: na fase de inspiração, os músculos da caixa torácica se contraem, proporcionando a entrada do ar para dentro dos alvéolos. Durante o repouso, a respiração é realizada quase que inteiramente pelos movimentos do diafragma, sendo que, durante a inspiração, sua contração puxa as superfícies inferiores dos pulmões para baixo fazendo com que o ar entre; e, na expiração, a retração elástica dos pulmões e da caixa torácica empurra este ar para fora. Ainda, os músculos intercostais externos aumentam o diâmetro anteroposterior da caixa torácica, ajudando na inspiração de repouso (5).

Por fim, vale ressaltar que os músculos acessórios podem ser utilizados na respiração de forma forçada (não em repouso). Podem ser inspiratórios como o músculo esternocleidomastoideo, os escalenos, serrátil anterior, dentre outros; e inspiratório, como os intercostais internos e os músculos abdominais (5).

\section{Principais parâmetros respiratórios}

\subsection{Volumes pulmonares}

Conhecendo os volumes normais da mecânica ventilatória, torna-se mais significativo o entendimento das variações usadas nos ventiladores mecânicos, que têm como principal objetivo, simular o processo fisiológico durante a falha de um dos componentes que auxiliam na respiração $(1,5)$.

- Volume corrente (VT): volume de ar mobilizado durante um ciclo respiratório; normalmente $(n \sim 500 \mathrm{~mL})$;

- Volume de reserva inspiratória: volume extra de ar que pode ser inspirado, além do volume corrente normal, quando a pessoa inspira com força total ( $n \sim 3000 \mathrm{~mL})$;

- Volume de reserva expiratória: máximo de volume extra de ar que pode ser expirado na expiração forçada, após o final de expiração corrente normal $(n \sim 1100 \mathrm{~mL})$;

- Volume residual: volume de ar que permanece nos pulmões após uma expiração forçada $(n \sim 1200 \mathrm{~mL})$.

\subsection{Capacidades pulmonares}

Ao descrever os eventos no ciclo pulmonar, algumas vezes, é desejável considerar dois ou mais volumes combinados (Figura 1); tais combinações são chamadas de capacidades pulmonares $(4,5)$. 


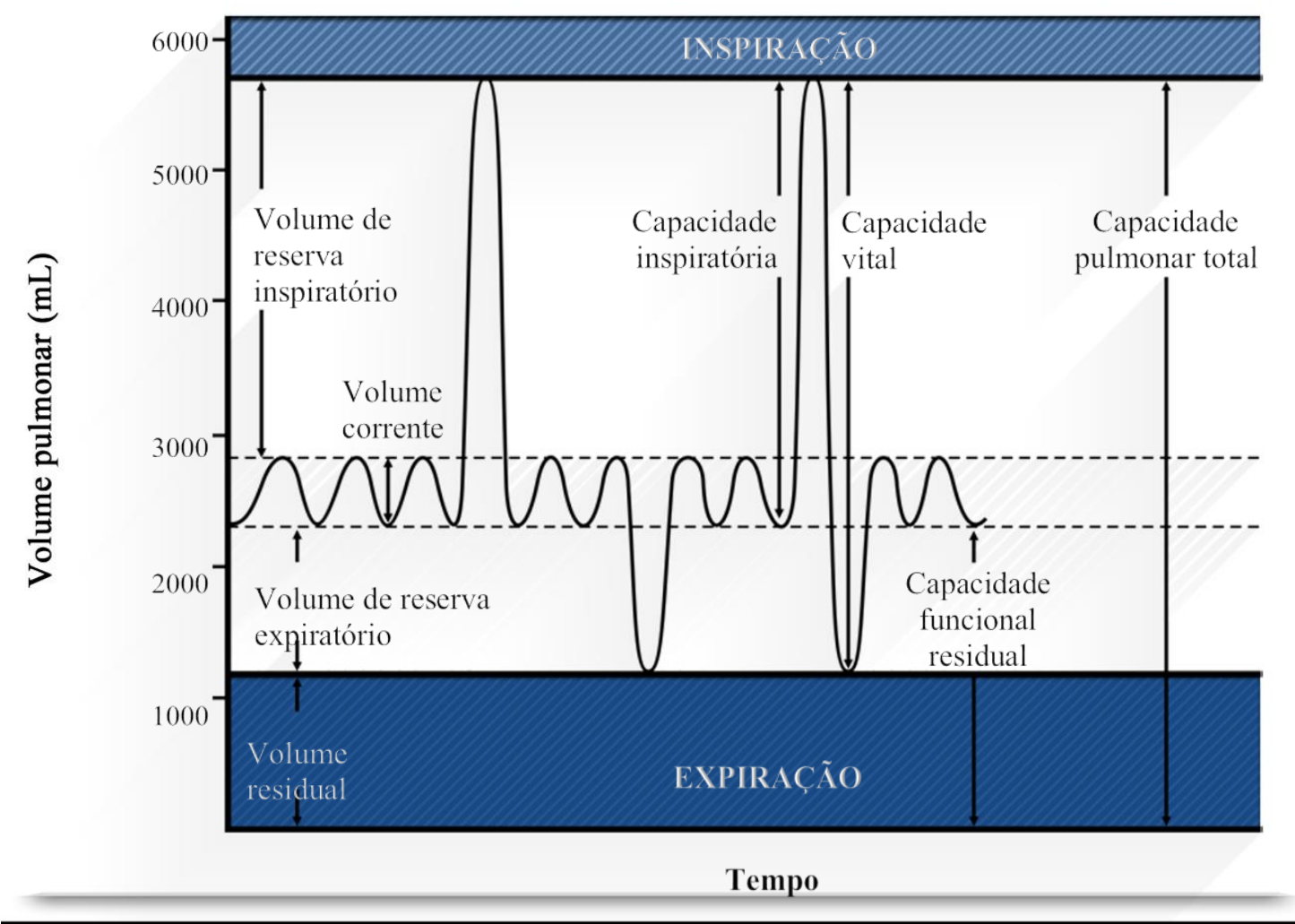

Figura 1 - Volumes e capacidades ventilatórias: diagrama das excursões respiratórias. Fonte - Elaborada pelos organizadores com adaptações (4).

- Capacidade inspiratória: é igual ao volume corrente mais o volume de reserva inspiratório. É a quantidade de ar $(n \sim 3500 \mathrm{~mL})$ que a pessoa pode respirar, começando a partir do nível expiratório normal e distendendo os pulmões ao seu máximo;

- Capacidade residual funcional: é igual ao volume de reserva expiratória mais o volume residual. É a quantidade de ar que permanece nos pulmões, ao final de expiração normal $(n \sim 2300 \mathrm{~mL})$;

- Capacidade vital: é igual ao volume de reserva inspiratória mais o volume corrente mais o volume de reserva expiratório. É a quantidade máxima de ar que a pessoa pode expelir dos pulmões, após primeiro enchê-los a sua extensão máxima e então expirar, também a sua extensão máxima $(n \sim 4600 \mathrm{~mL})$;

- Capacidade pulmonar total: é o volume máximo a que os pulmões podem ser expandidos com o maior esforço $(n \sim 5800 \mathrm{~mL})$, é igual a capacidade vital mais o volume residual. Todos os volumes e capacidades pulmonares, nas mulheres, são cerca de 20 a $25 \%$ menores que nos homens, e são maiores em pessoas atléticas e com massas corporais maiores do que em pessoas menores e astênicas.

\section{Espaço morto}

Parte do ar que a pessoa respira nunca alcança as áreas de trocas gasosas, por simplesmente preencher as vias respiratórias onde essas trocas nunca ocorrem, tais como o nariz, a faringe e a traqueia. Na expiração, o ar do espaço morto é expirado primeiro, antes de qualquer ar dos alvéolos alcançar a atmosfera. Portanto, o espaço morto anatômico é muito desvantajoso para remover os gases expiratórios dos pulmões. Ocasionalmente, alguns dos próprios alvéolos podem não ser funcionantes por causa da ausência ou redução do fluxo sanguíneo pelos capilares pulmonares; assim, do ponto de 
vista funcional, esses alvéolos também devem ser considerados como parte do espaço morto (espaço morto fisiológico). Algumas entidades podem causar o aumento desse espaço morto, como: hipovolemia, hipertensão pulmonar, embolia pulmonar e a hiperdistensão alveolar (5).

\section{Tipos de ventilação mecânica}

Na VM uma pressão subatmosférica é criada nas vias respiratórias superiores; tal gradiente pressórico propulsiona o gás através da árvore brônquica até atingir os alvéolos, o que se repete a cada ciclo respiratório tendo início na fase inspiratória (1). Nas duas situações (Figura 2), a VM é conseguida com a aplicação de pressão positiva nas vias aéreas $(1,6)$. A diferença entre ela é a forma de liberação dessa pressão:

- VM não invasiva: utiliza-se uma máscara, bem acoplada, como interface entre o paciente e o ventilador artificial;

- VM invasiva: utiliza-se uma prótese traqueal (tubo oro/nasotraqueal ou cânula de traqueostomia).

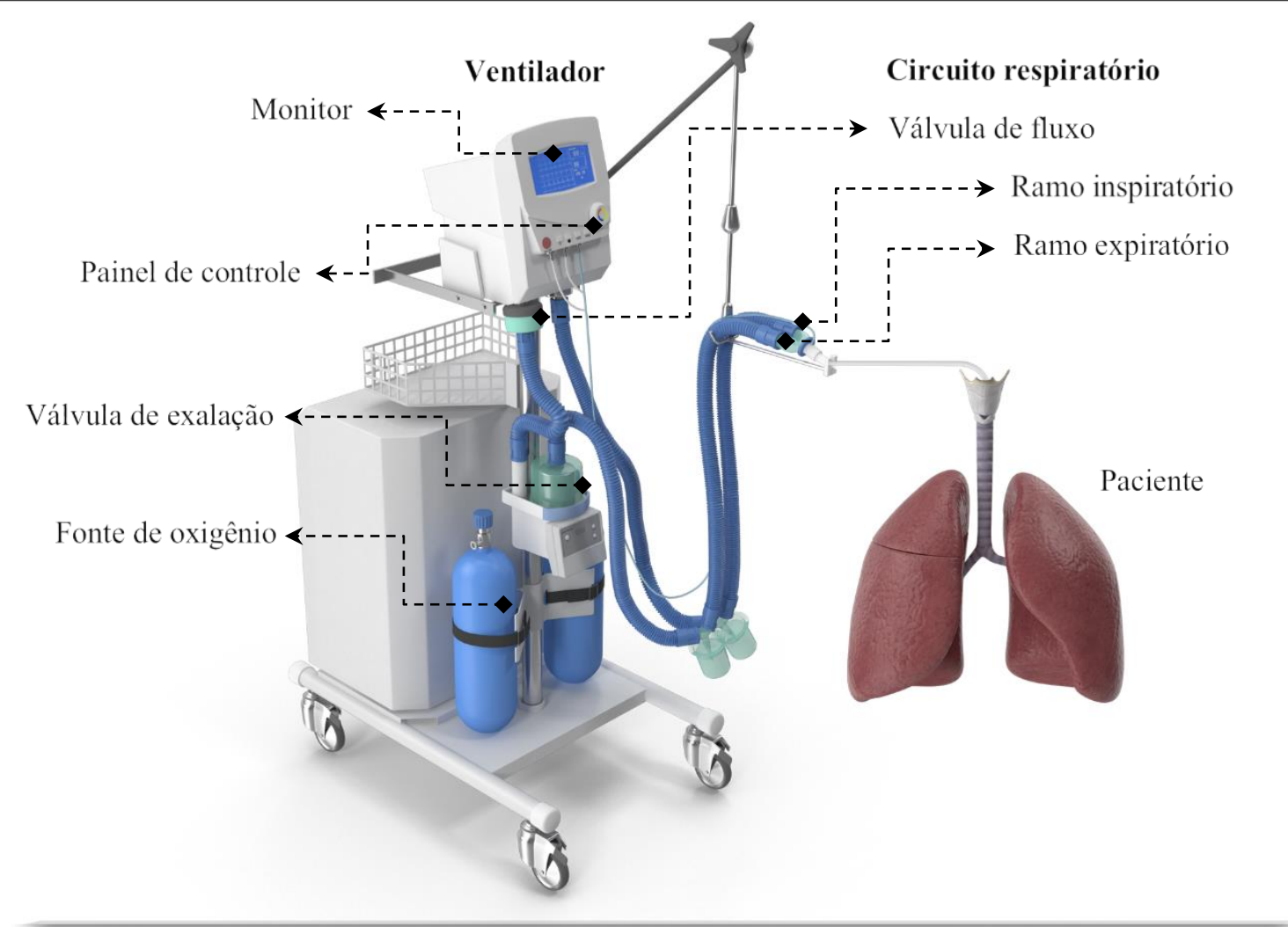

Figura 2 - Sistemas de ventilação.

Fonte - Elaborada pelos organizadores com adaptações (4).

A partir de uma representação simplificada do sistema ventilatório e de um ventilador mecânico, vamos começar a descrever os mecanismos envolvidos. O modelo conta com:

- válvula de fluxo;

- válvula de exalação;

- transdutores de pressão e fluxo;

- painel de controle;

- monitor;

- circuito de controle. 
A válvula de fluxo é ligada a uma fonte de ar e/ou oxigênio. Internamente há uma esfera atuando sobre uma sede, que controla a abertura e passagem do gás. A posição da esfera em relação a sede é o que define o fluxo inspiratório. A saída da Válvula de fluxo é ligada ao ramo inspiratório do circuito do paciente. A extremidade do ramo expiratório do circuito do paciente é ligada à válvula de exalação. A atuação de um diafragma sobre um bocal é o que controla a abertura e fechamento do ramo expiratório. Os sinais de pressão e fluxo são medidos na saída do "Y" do circuito respiratório (encontro do ramo expiratório e do ramo inspiratório), onde é conectado o tubo endotraqueal (interface paciente-ventilador). A medição da pressão é realizada pelo transdutor de pressão das vias aéreas (Pva), que transforma o sinal pneumático em sinal elétrico (1). A medição do fluxo pelo transdutor de fluxo pode ser realizada em diversos pontos do sistema; existem ventiladores que realizam a medida de fluxo na saída da válvula de fluxo (fluxo inspiratório), e/ ou na saída da válvula de exalação (fluxo expiratório). A medida do volume é obtida através do sinal de fluxo. O fluxo representa a velocidade com que um determinado volume de fluido está se movimentando (1). A partir dos controles efetuados através do painel de controles e da monitorização realizada pelos transdutores de pressão e fluxo, é realizado o controle das válvulas de fluxo e exalação através do circuito de controle do ventilador. $\mathrm{O}$ ventilador inicia a fase inspiratória abrindo a válvula de fluxo e fechando a válvula de exalação; nessa fase ocorre o enchimento dos pulmões com o ventilador exercendo a pressão necessária para vencer o atrito nas vias aéreas e expandir os pulmões (1). O final da fase inspiratória irá coincidir com o início da fase expiratória, com o ventilador fechando a válvula de fluxo e abrindo a válvula de exalação; nessa fase ocorre o esvaziamento do pulmão, sendo que a força motriz é a própria pressão no interior do pulmão, ou seja, via de regra, a exalação é passiva (1).

Assim, os sinais de pressão, fluxo e volume podem ser representados graficamente:

- Gráfico 1: Fluxo (L/min) X Tempo (s): a válvula de fluxo é aberta no instante $1 \mathrm{~s}$ (início da fase inspiratória) e o fluxo atinge o valor de $30 \mathrm{~L} / \mathrm{min}$; o valor positivo indica que o fluxo é inspiratório. O fluxo é mantido constante até o $2 \mathrm{~s}$, nesse instante a válvula de fluxo é fechada e fluxo cai a zero. Simultaneamente, a válvula de exalação é aberta (início da fase expiratória) e o gás de dentro dos pulmões é exalado pela própria pressão no interior dos pulmões. $\mathrm{O}$ fluxo atinge um valor de $-40 \mathrm{~L} / \mathrm{min}$, o valor negativo indica que o fluxo é expiratório. À medida que o pulmão esvazia, diminui a pressão no seu interior e consequentemente o fluxo expiratório. $\mathrm{O}$ fluxo expiratório zero indica o esvaziamento total dos pulmões no instante $3 \mathrm{~s}$. No instante $4 \mathrm{~s}$ é iniciado um novo ciclo.

- Gráfico 2: Volume (L) X Tempo (s): no instante $1 \mathrm{~s}$ é iniciado o enchimento dos pulmões através de um fluxo inspiratório de $30 \mathrm{~L} / \mathrm{min}$. O volume inspirado é a área definida entre a curva de fluxo inspiratório e o eixo tempo; e o exalado é a área definida pelo fluxo expiratório. Como nesse caso o fluxo é mantido constante, o volume aumenta linearmente, até o valor de 0,5 L no instante $2 \mathrm{~s}$. Nesse instante, com o fechamento da válvula da válvula de fluxo e abertura da válvula de exalação, inicia-se o esvaziamento dos pulmões, com o volume retornando a zero no instante $3 \mathrm{~s}$. Durante a exalação o volume diminui de forma exponencial.

- Gráfico 3: Pressão $\left(\mathrm{cmH}_{2} \mathrm{O}\right) \mathrm{X}$ Tempo (s): com o início do fluxo inspiratório no instante $1 \mathrm{~s}$, ocorre um aumento abrupto de pressão nas vias aéreas, correspondendo à pressão necessária para vencer o atrito e movimentar os gases através das vias áreas (componente resistivo). À medida que ocorre a expansão dos pulmões, e a distensão das estruturas viscoelásticas, ocorre um aumento proporcional de pressão, necessária para vencer as forças viscoelásticas do parênquima pulmonar e da parede torácica (componente elástico). A pressão atinge seu pico máximo no instante $2 \mathrm{~s}$, quando ainda existe fluxo inspiratório e os pulmões atingiram seu volume máximo durante o ciclo. A 
pressão retorna ao valor inicial - linha de base - durante a exalação. A pressão da linha de base, durante a fase expiratória, pode ser mantida acima da pressão atmosférica, através do controle do controle da válvula de exalação. Ou seja, a válvula de exalação pode permanecer parcialmente fechada, impedindo a saída de todo o volume de gás do interior dos pulmões. Nesse caso a pressão expiratória é mantida positiva (PEEP).

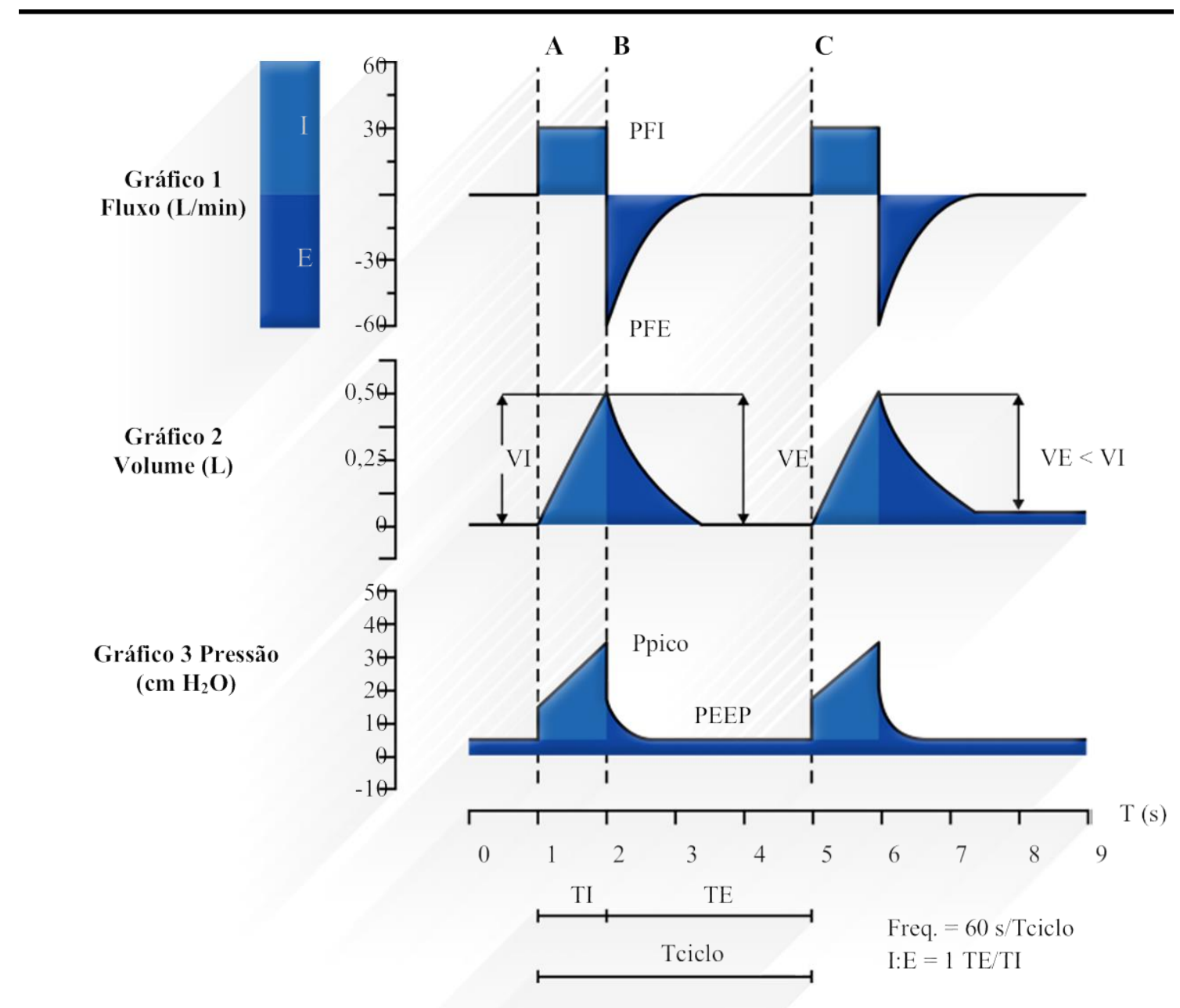

Figura 3 - Representação gráfica da Ventilação mecânica (modo ventilação volume controlada).

Ponto A: início da fase inspiratória (abertura da válvula de fluxo e fechamento da válvula de exalação). Ponto B: início da fase expiratória (fechamento da válvula de fluxo e abertura da válvula de exalação). Ponto C: início de um novo ciclo respiratório.

Fonte - Elaborada pelos organizadores com adaptações (4).

\section{Principais parâmetros respiratórios}

A VM se faz através de aparelhos que, intermitentemente, insuflam as vias aéreas com volumes de ar (volume de ar corrente - VT ou VAC) (6). O movimento do gás para dentro dos pulmões ocorre devido a geração de um gradiente de pressão entre as vias aéreas superiores e os alvéolos; os mais usados são os aparelhos que aumentam a pressão nas vias aérea proximal (ventilação por pressão positiva). Neste ar inspirado, controla-se a concentração de $\mathrm{O}_{2}$ ou fração inspirada de $\mathrm{O}_{2}\left(\mathrm{FiO}_{2}\right)$, entre 21 a $100 \%$, necessária para se obter uma taxa arterial de oxigenação (pressão parcial de oxigênio no sangue arterial $\mathrm{PaO}_{2}$ ) adequada. Controla-se ainda, a velocidade com que o ar será administrado, o fluxo 
inspiratório (V) e, também, define-se a forma da onda de fluxo (descendente, quadrada, ascendente ou sinusoidal) como no modo de ventilação controlado a volume (6). O número de ciclos respiratórios que os pacientes realizam em um minuto é a frequência respiratória (f), consequência do tempo inspiratório (TI), que depende do fluxo e do tempo expiratório (TE) (6).

\subsection{Volume corrente (VT ou VAC)}

Ao utilizarmos um modo em que o volume corrente pode ser diretamente ajustado, devemos através da determinação do VT e da $f$, impor ao paciente o volume minuto desejado. Em geral, baixos volumes em torno de 6 a $8 \mathrm{~mL} / \mathrm{Kg}$ (de peso predito) são recomendados, por constituírem a ventilação protetora. Sabe-se que volumes que superem a capacidade pulmonar total geram pressões elevadas e podem resultar em lesão pulmonar (barotrauma), além da própria lesão devido a hiperdistensão (volutrauma) (9).

\subsection{Fração inspirada de oxigênio $\left(\mathrm{FiO}_{2}\right)$}

Deverá ser ajustada para a obtenção de uma oxigenação adequada. Valores entre 21 e $100 \%$ podem ser utilizados, mas devemos lembrar a toxicidade causada pelo uso prolongado de altas concentrações de oxigênio. Uma $\mathrm{FiO}_{2}$ maior que $60 \%$ quando utilizado por períodos maiores que 72 horas pode causar fibrose pulmonar. A recomendação é iniciar a ventilação com $\mathrm{FiO}_{2}$ de $100 \%$ que será reduzida com base na saturação periférica de oxigênio e nos resultados da gasometria arterial (9).

\subsection{Frequência respiratória (f) e Fluxos}

A frequência respiratória deve ser baseada na demanda do paciente e no modo ventilatório utilizado. Nos pacientes submetidos a intensa sedação a frequência ajustada será a total e deve ficar entre 14 e 18 ciclos por minuto. A Síndrome da Angústia Respiratória do Adulto (SARA) e acidose grave podem indicar uma necessidade de maior volume minuto para ajuste do $\mathrm{pH}$ arterial com maior retirada de gás carbônico. Em modos espontâneos ou assistidos a frequência é determinada pelo paciente cujo drive será fundamental no ajuste da frequência. $\mathrm{O}$ ajuste da relação entre o tempo inspiratório e expiratório é de grande importância e em geral deve ser 1:2 ou maior.

\subsection{Pressão Positiva ao Final da Expiração}

A Pressão Positiva ao Final da Expiração (PEEP) inicial deverá ser aquela que substitua o fisiologicamente gerado pelo fechamento glótico, em torno de $3 \mathrm{cmH}_{2} \mathrm{O}$. A implementação de níveis entre 5-8 $\mathrm{cmH}_{2} \mathrm{O}$ de PEEP melhoram a oxigenação e ainda reduz a frequência de atelectasias, ou seja, um valor que recrutaria alvéolos sem gerar a hiperinsuflação pulmonar (1). Além disso, não existe um valor fixo de PEEP, sendo sempre necessário obter seu valor de acordo com a necessidade de cada paciente.

\subsection{Pressão de Platô}

A pressão de platô consiste na pressão inspiratória final, ou seja, é a pressão de acomodação dos alvéolos no final da inspiração. Seus valores desejáveis são abaixo de $30 \mathrm{cmH}_{2} \mathrm{O}$ e ela pode ser obtida nos ventiladores quando se ajusta uma pausa inspiratória que geralmente situa-se entre $10 \%$ e $30 \%$ no modo volume controlado. 


\subsection{Drive Pressure}

O Drive Pressure consiste no componente de distensão alveolar e pode ser calculado pela diferença entre a pressão de platô e a PEEP. Seus valores devem situar-se abaixo de 13-15 $\mathrm{cmH}_{2} \mathrm{O}$. O Drive Pressure, associado a baixos volumes correntes são parâmetros para uma ventilação mecânica protetora.

\subsection{Ciclo ventilatório}

O ciclo ventilatório (Figura 4), durante a ventilação com pressão positiva, é dividido em 4 fases (6):

a) Fase inspiratória: fase do ciclo em que o ventilador realiza a insuflação pulmonar, conforme as propriedades elásticas e resistivas do sistema respiratório;

b) Mudança de fase inspiratória para a fase expiratória (ciclagem): transição entre a fase inspiratória e expiratória; o ventilador deverá interromper a fase inspiratória;

c) Fase expiratória: momento seguinte ao fechamento da válvula inspiratória e abertura da válvula expiratória, permitindo que a pressão do sistema respiratório se equilibre com a pressão expiratória final determinada pelo ventilador;

d) Mudança da fase expiratória para a fase inspiratória (disparo): fase em que termina a expiração e ocorre o disparo (abertura da válvula inspiratória) do ventilador, iniciando uma nova fase inspiratória.

\section{CURVA DE FLUXO - VENTILAÇÃO CONTROLADA POR VOLUME}

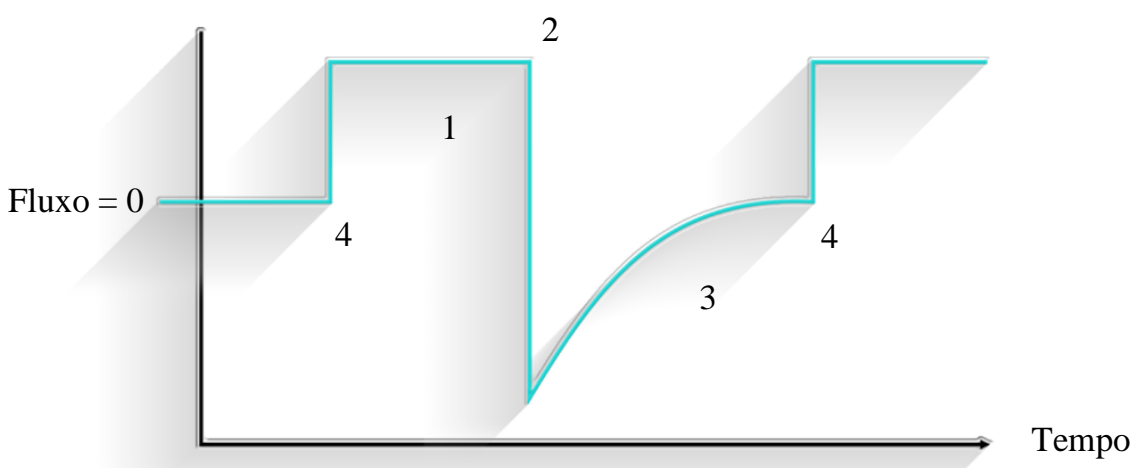

Figura 4 - Fases do ciclo ventilatório.

Fonte - Elaborada pelos organizadores com adaptações (4).

A ciclagem do ventilador da fase inspiratória para a fase expiratória muda conforme a modalidade ventilatória. No modo de pressão controlada a ciclagem se dá por tempo inspiratório ou com a relação TI-TE, no modo volume controlado pelo volume corrente pré-estabelecido e no modo de pressão de suporte pelo fluxo.

\section{Ventilação mecânica protetora}

A ventilação volume controlada (VVC) e a ventilação pressão controlada (VPC) não são diferentes modos ventilatórios, mas sim variáveis de controle do modo ventilatório (Figura 3) (6). A melhor forma de selecionar qual variável de controle deverá ser usada é conhecer as suas principais vantagens e desvantagens e relacionar ao quadro clínico do paciente. O objetivo da VM é simular a mecânica ventilatória fisiológica do paciente, e 
um dos conceitos básicos é o entendimento do conceito chamado "ventilação mecânica protetora" definido como volume corrente de 6-8 mL/kg, PEEP menor que $5 \mathrm{cmH}_{2} \mathrm{O}$ (valor ainda é centro de discussões entre especialistas), uma pressão de platô menor que $30 \mathrm{cmH}_{2} \mathrm{O}$ e uma Drive Pressure menor que $13-15 \mathrm{cmH}_{2} \mathrm{O}$.

\section{Modos ventilatórios}

\subsection{Ventilação mecânica controlada}

É a mais tradicional, podendo ser "volume-controlada" ou "pressão-controlada". Nesta o ventilador inicia e termina a inspiração de acordo com um tempo subordinado a uma frequência respiratória preestabelecida. Uma vez que o ventilador determina o VT, V e a Relação do tempo inspiratório-expiratório (I:E) o paciente não participa ativamente da ventilação. Assim, esse modo deve ser reservado a pacientes em apneia (por sedação, bloqueio neuromuscular ou mesmo doença neurológica).

No modo volume controlado, fixam-se a f, o VT e o V. O disparo ocorre de acordo com a f estabelecida (p. ex., $f$ de 15 irpm, o disparo ocorrerá a cada 4 s) e a ciclagem acontece após a entrega do VT pré-estabelecida.

No modo de pressão controlada, fixam-se a f, o tempo inspiratório ou a relação inspiração-expiração (TI-TE) e o limite da pressão inspiratória. O disparo continua predeterminado pela frequência respiratória e a ciclagem passa a depender do tempo inspiratório ou da relação TI-TE.

\subsubsection{Ventilação volume controlada}

Na VVC determina-se o volume que será oferecido ao paciente em cada respiração mandatória ao determinar-se o tempo de inspiração ou o fluxo. Dessa maneira, o volume se mantém constante, não sendo influenciado por fatores como a complacência, o volume dos pulmões, a musculatura respiratória e a resistência das vias aéreas; essa, compõemse a principal vantagem da VVC. Nesse tipo de controle é possível atingir altas pressões na via aérea, em decorrência do aumento da resistência, uso da musculatura respiratória ou redução da complacência (7). Assim, quando há alterações nesses componentes da mecânica ventilatória, torna-se mais claro as desvantagens da VVC: que pode ocasionar uma ventilação alveolar excessiva aumentando o espaço morto na via aérea; ou provocar áreas de hiperdistensão.

\subsubsection{Ventilação pressão controlada}

Na VPC, de forma semelhante ao volume controlada, a pressão é determinada no ventilador mecânico, não sofrendo variações com alterações na complacência, resistência ou esforço respiratório do paciente. Nesse modo, o ventilador rapidamente produz um fluxo para atingir a pressão inspiratória predefinida, o qual se reduz ao longo da inspiração, sendo, portanto, desacelerado. As principais vantagens dessa variável é que as características do fluxo podem variar conforme a necessidade do paciente, promovendo, assim, maior conforto ao paciente; e a proteção, através do limite da pressão inspiratória, das lesões ocasionadas por hiperdistensão (6).

A desvantagens dessa variável é a grande variação de volume de ar corrente a cada ciclo, devido a impedância do sistema respiratório, que podem provocar a redução do volume minuto e hipoxemia. Durante a respiração passiva, pacientes saudáveis possuem uma curva de fluxo inspiratório sinusoidal. Na VPC, institui-se uma curva em formato de onda 
de fluxo desacelerado. Atualmente, é aceito que esse fluxo desacelerado é associado a melhor distribuição do gás, menores pressões nas vias aéreas, mais conforto ao paciente, com redução do trabalho respiratório (6).

\subsection{Ventilação assistida/controlada (A/C)}

$\mathrm{Na}$ ventilação assistida, o início da inspiração é determinado por fluxo ou pressão negativa gerada por esforço respiratório do paciente (assistido). Assim, a $f$ e os tempos I:E estão vinculados ao drive do paciente. Para esse modo ventilatório, o comando da sensibilidade do ventilador deve ser ajustado; esse dispositivo permite regular o nível de esforço respiratório mínimo que o paciente deve gerar para iniciar a inspiração. Caso o paciente não atinja o valor predeterminado de sensibilidade para disparar o aparelho (trigger), este manterá ciclos ventilatórios de acordo com a $f$ mínima indicada pelo operador (ventilação de backup) (6).

\subsection{Ventilação Mandatória Intermitente (IMV) e Ventilação Mandatória Intermitente Sincronizada (SIVM)}

A IMV é uma combinação de ciclos espontâneos e ciclos assistidos com volume corrente ou pressão controlada previamente ajustados. Dessa forma uma frequência predeterminada de IMV é utilizada a intervalos fixos, e entre esses ciclos o paciente pode respirar espontaneamente gás enriquecido com oxigênio (6).

O modo SIVM é em geral o preferido, uma vez que ajusta ciclos espontâneos e mandatórios de tal maneira que não haja coincidência entre eles; nesta modalidade o respirador impõe um período refratário após cada ciclo espontâneo, não permitindo que um ciclo mandatório seja iniciado enquanto o paciente expira. Esse modo ventilatório pode ser ajustado por volume ou pressão controlada (6):

- SIVM com volume controlado: determina-se a f, o VT e o V, além do critério de sensibilidade para a ocorrência do disparo do ventilador pelo paciente. Assim, permite-se que o ventilador aplique os ciclos mandatórios pré-determinados em sincronia com o esforço inspiratório do paciente. Se o paciente entrar em apneia, o próximo ciclo será disparado por tempo até que retornem as incursões respiratórias do paciente.

- SIVM com pressão controlada: de forma semelhante ao de volume controlado, nesse modo os parâmetros definidos pelo operador passam a ser a f, o tempo respiratório ou a relação I:E e o limite da pressão inspiratória, além do critério da sensibilidade para a ocorrência do disparo do ventilador pelo paciente.

\subsection{Ventilação com pressão de suporte}

Modo de ventilação mecânica espontânea, ou seja, disparado e ciclado pelo paciente, em que o ventilador assiste à ventilação através da manutenção de uma pressão positiva pré-determinada durante a inspiração até que o $\mathrm{V}$ do paciente se reduza a um nível crítico, normalmente $25 \%$ do pico de $\mathrm{V}$ atingido. Por ser um modo de ventilação puramente espontâneo, exige que o paciente tenha um bom drive respiratório. Por ser confortável para o paciente desperto e permitir redução gradual do suporte ventilatório tem sido utilizado para ventilação e desmame com grande aceitação (6). 


\subsection{SIVM associada a ventilação com pressão de suporte}

Existe a combinação das ventilações mandatórias sincronizadas com ventilações espontâneas assistidas através da pressão inspiratória pré-estabelecida (6).

\subsection{Pressão positiva contínua nas vias aéreas (CPAP)}

$\mathrm{O}$ ventilador permite que o paciente ventile espontaneamente, porém oferece uma pressurização continua tanto na inspiração quanto na expiração. Esse é um modo de ventilação espontânea não assistida pelo ventilador (6).

\section{Indicações}

Agora que já aprendemos sobre a fisiologia da mecânica ventilatória, os tipos de ventilação mecânica associada aos seus principais parâmetros respiratórios, se faz necessário compreender as principais indicações para se iniciar o suporte ventilatório que são (6):

- reanimação devido a parada cardiorrespiratória;

- $\quad$ hipoventilação e apneia;

- insuficiência respiratória devido a doença pulmonar intrínseca e hipoxemia;

- falência mecânica do aparelho respiratório:

- fraqueza muscular, doenças neuromusculares e paralisia;

- comando respiratório instável (trauma craniano, acidente vascular cerebral, intoxicação exógena e abuso de drogas);

- prevenção de complicações respiratórias;

- restabelecimento no pós-operatório de cirurgia de abdome superior ou torácica de grande porte;

- $\quad$ parede torácica instável;

- redução do trabalho muscular respiratório e fadiga muscular.

\section{Considerações finais}

Mais importante, até mesmo antes de saber como se utiliza um ventilador mecânico, com seus diferentes ajustes e modos ventilatórios, é identificar os pacientes de risco e que poderão evoluir de forma rápida para uma insuficiência respiratória, que irão inevitavelmente necessitar de um suporte ventilatório. Após uma correta indicação e ajuste deste paciente a um ventilador mecânico, é de suma importância dar adequadas condições para que este paciente se mantenha o mais confortável possível, enquanto a sua doença de base é tratada (Quadro 1).

Um novo conceito que vem surgindo é o da ventilação mecânica protetora, onde são utilizados alguns parâmetros como baixo volume corrente e baixo drive pressure, que diminuem a inflamação ocasionada pela ventilação mecânica, tornando a recuperação dos pacientes mais rápida e eficaz, gerando menor morbimortalidade e menos custos ao sistema de saúde. 
Quadro 1 - Tópicos em destaque no capítulo.

\section{VENTILAÇÃO MECÂNICA}

Estudar para compreender a fisiologia da mecânica respiratória.

Reconhecer rapidamente aqueles pacientes que poderão necessitar de um suporte ventilatório.

Saber o funcionamento básico dos ventiladores mecânicos, além dos ajustes dos parâmetros ventilatórios.

Ao oferecer um suporte ventilatório, realizar sempre uma VM protetora ao seu paciente.

Reconhecer cada quadro clínico e saber a melhor hora de iniciar o desmame ventilatório.

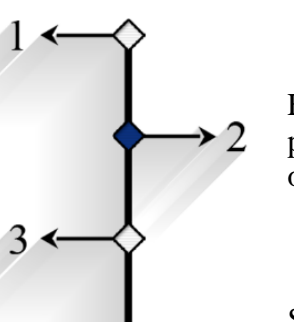

Entender os volumes, capacidades pulmonares, frequência respiratória e outros parâmetros dos pacientes.

Saber de forma precisa as indicações da VM e como proceder até conseguir oferecer este suporte ventilatório.

\section{Entender e utilizar as diferentes} modalidades ventilatórias, bem como ajustá-las a cada tipo de paciente.

Manter o paciente ajustado ao ventilador, ofertando-lhe o melhor conforto possível enquanto trata a sua doença de base.

Retirar o mais breve possível da VM os pacientes em que este suporte não lhe é mais útil.

\section{Referências}

1. Bonassa J. Princípios Básicos dos Ventiladores Artificiais. In: Carvalho CRR. Ventilação Mecânica. São Paulo: Editora Atheneu; 2000.

2. Machado FD, Eder GL, Dullius CR, Baldisserotto S. Ventilação mecânica: como iniciar. Acta méd; Porto Alegre 2014; 35(8): 1-8.

3. Tarantino AB. Doenças pulmonares. Rio de Janeiro: Guanabara Koogan; 2008.

4. Raff H, Levitzky M. Fisiologia Médica: Uma abordagem integrada. Porto Alegre: Artmed; 2012.

5. Hall JE, Guyton AC. Guyton \& Hall Tratado de Fisiologia Médica. Rio de Janeiro: Elsevier; 2017.

6. Carvalho RRC, Toufen Júnior C, Franca AS. III Consenso Brasileiro de Ventilação Mecânica; J Bras Pneumol 2007; 33(2): 54-70.

7. Araújo DA, Cunha de Leão BC, Ferreira RS. Volume x Pressão. Qual escolher? Rev Med Minas Gerais 2014; 24(8): 49-55.

8. Campbell RS. Pressure-controlled versus Volume-controlled ventilation: does in matter? Respir Care 2002; 47(4): 416-24.

9. Pádua AI, Martinez JAB. Modos de assistência ventilatória. Medicina, Ribeirão Preto 2001;34: 13342. 